\title{
Determinan Penggunaan Metode Kontrasepsi Jangka Panjang (MKJP) pada Akseptor KB
}

\author{
Indah Budiarti $^{1}$, Dina Dwi Nuryani ${ }^{2}$, Rachmat Hidayat ${ }^{3}$ \\ ${ }^{1,2,3}$ Fakultas Kesehatan Masyarakat, Universitas Malahayati \\ Email: indahbudiarti29@gmail.com
}

\begin{abstract}
The Determinant of Using Long Term Birth Contraceptive Method (LTBCM) on KB Acceptor. The main problem that Indonesia faces in demography is the high population growth. Efforts in realizing quality family has the main goal to control the population growth and to improve the quality of small size family which is indicated with the use of rational, effective and efficient birth control method, the long term birth control method (LTBCM). Kalirejo public health center in gaining LTBCM tended to decrease in the last two years from $10,87 \%$ to $10,62 \%$. The pre-survey result in October 2016 showed reduced LTBCM of 377 fertile age couples $(10,62 \%)$ from 3555 birth control acceptors. The objective of this research was to find out the determinants of a long term birth control method used in the birth control acceptors in Kalirejo public health center working area in Negeri Katon sub district of Pesawaran in 2017. This was an analytic research with cross sectional approach. The research population was all active birth control acceptors in Kalirejo public health center with 360 samples of acceptors of LTBCM and non- LTBCM. Primary data were collected with questionnaires and analyzed by using univariate, bivariate and multivariate analyses. The research results showed that $75,3 \%$ respondents used nonLTBCM, 57,2\% risks not to use LTBCM, 56,7\% unemployed, 65,3\% respondents were in risks to have more children, $83,6 \%$ respondents were supported by their couples. Bivariate analysis result found correlations of age $(p=0,007)$, occupation $(p=0,000)$, couple's support $(p=0,000)$, to the use of LTBCM. Amount of child $(\mathrm{p}=0,208)$ did not correlate with the use of LTBCM. The researcher recommends that the local public health centers should conduct education of the active birth control acceptors to use the LTBCM as the role models for new acceptor candidates which in turn will enhance the coverage of the LTBCM services in their working areas.
\end{abstract}

Keywords: LTBCM, Birth control acceptor

\begin{abstract}
Abstrak: Determinan Penggunaan Metode Kontrasepsi Jangka Panjang (MKJP) pada Akseptor KB. Masalah utama yang dihadapi Indonesia di bidang kependudukan adalah pertumbuhan penduduk yang masih tinggi. Upaya mewujudkan keluarga berkualitas, sasaran utamanya adalah terkendalinya pertumbuhan penduduk dan meningkatnya keluarga kecil berkualitas ditandai meningkatnya penggunaan metode kontrasepsi yang rasional, efektif dan efesien yakni MKJP. Puskesmas Kalirejo dalam pencapaian MKJP cenderung menurun dalam waktu dua tahun terakhir dari 10,87 \% menjadi 10,62\%. Pendataan prasurvey bulan Oktober 2016 pencapaian MKJP menurun yakni sebesar 377 PUS atau sekitar 10,62\% dari 3551 akseptor KB. Tujuan penelitian untuk mengetahui determinan penggunaan metode kontrasepsi jangka panjang (MKJP) pada akseptor KB di wilayah kerja Puskesmas Kalirejo Kecamatan Negeri Katon Kabupaten Pesawaran Tahun 2017. Rancangan penelitian analitik dengan pendekatan cross sectional. Populasi penelitian adalah akseptor KB aktif di Puskesmas Kalirejo dengan sampel sebanyak 360 akseptor MKJP dan Non MKJP. Pengumpulan data primer menggunakan kuesioner dengan analisa univariat, bivariat dan multivariat. Hasil penelitian sebagian besar responden menggunakan Non MKJP (75,3\%), umur berisiko (57,2\%), tidak bekerja $(56,7 \%)$, jumlah anak berisiko $(65,3 \%)$, didukung suami/pasangan $(83,6 \%)$. Analisa bivariat adanya hubungan umur $(\mathrm{p}=0,007)$, pekerjaan $(\mathrm{p}=0,000)$, dukungan suami/pasangan $(\mathrm{p}=0,000)$. Jumlah anak $(\mathrm{p}=0,208)$ tidak berhubungan dengan penggunaan MKJP. Sebaiknya puskesmas setempat tetap melakukan pembinaan kepada akseptor KB aktif yang menggunakan MKJP agar tetap sebagai percontohan (role model) bagi calon akseptor yang baru, dengan demikian nantinya dapat meningkatkan cakupan pelayanan MKJP di wilayah kerjanya.
\end{abstract}

Kata kunci: MKJP, Akseptor KB

Masalah utama yang dihadapi oleh Indonesia di bidang kependudukan adalah pertumbuhan penduduk yang masih tinggi.
Semakin tingginya pertumbuhan penduduk maka semakin besar usaha yang dilakukan untuk mempertahankan kesejahteraan rakyat. Ancaman 
terjadinya ledakan penduduk di Indonesia semakin nyata.

Mewujudkan derajat Kesehatan Ibu yang setinggi-tingginya adalah salah satu agenda pembangunan yang sejalan dengan Tujuan Pembangunan Berkelanjutan (Sustainable Development Goals - SDGs). Hal tersebut juga sesuai dengan arah Pembangunan Pemerintahan periode 2015- 2019, untuk mewujudkan Agenda Prioritas Pembangunan (Nawacita), terutama pada Agenda Prioritas nomor 5 (lima) yaitu "Meningkatkan Kualitas Hidup Manusia Indonesia" mel melalui "Pembangunan Kependudukan dan Keluarga Berencana" (BKKBN, 2015).

Upaya untuk mewujudkan keluarga berkualitas, sasaran utamanya adalah terkendalinya pertumbuhan penduduk dan meningkatnya keluarga kecil yang berkualitas, ditandai dengan meningkatnya penggunaan metode kontrasepsi yang rasional, efektif dan efesien (REE). Metoda kontrasepsi yang memenuhi unsur efektif dan efesien adalah metoda kontrasepsi Alat Kontrasepsi Dalam Rahim (AKDR) Intra Uterine Device (IUD), Metode Operasional Wanita (MOW), Metode Operasional Pria (MOP) dan Implan/ susuk, efektif untuk mencegah kehamilan dan biayanya lebih murah, karena sekali membayar pelayanan dapat digunakan dalam waktu yang panjang, sehingga disebut metoda kontrasepsi jangka panjang (MKJP).

Rata-rata penggunaan kontrasepsi di ASEAN dari tahun 2005-2012 tertinggi adalah Negara Thailand yaitu $80 \%$, kemudian disusul Kamboja 79\%. Sedangkan Indonesia penggunaan kontrasepsi masih dibawah kedua negara tersebut yaitu hanya sekitar $61 \%$ (Kemenkes, 2013). Pada tahun 2014 cakupan KB aktif di Indonesia sebesar $61,75 \%$, dan pada tahun 2015 jumlah Pasangan Usia Subur (PUS) sebanyak 48,609 juta pasangan dengan pencapaian KB aktif sebesar $59,98 \%$. Berdasarkan provinsi, cakupan KB aktif tertinggi tahun 2015 adalah Provinsi Kalimantan Selatan sebesar $70,13 \%$, dan yang terendah yaitu Provinsi Papua sebesar 23,37\%. Sedangkan untuk Metode Kontrasepsi Jangka Panjang (MKJP) seperti IUD, MOW, Implant dan MOP di Indonesia sendiri pada tahun 2014 untuk pencapaiannya hanya sekitar 15,5\% dan pada tahun 2015 cakupannya mencapai $17,01 \%$ dengan rincian peserta IUD $(7,3 \%)$, peserta MOW (3,23\%), peserta Impant sebanyak $(6,21 \%)$ serta peserta KB pria yakni MOP $(0,27 \%)$ (Hartanto, $\mathrm{W}, 2015)$.

Provinsi Lampung menurut data Susenas 2015 (dalam Hartanto, W, 2015) termasuk dalam 5 provinsi dalam kategori tertinggi berdasarkan cakupan KB aktif yaitu peringkat pertama adalah Provinsi Kalimantan Selatan (70,13\%), Kalimantan
Tengah (68,50\%), Sumatera Selatan (68.06\%), Bengkulu (67,83\%), dan Lampung (67,35\%). Provinsi Lampung dalam pencapaian MKJP sebesar $33,64 \%$ pada tahun 2014 , dan pada tahun 2015 mengalami peningkatan sekitar $0,7 \%$ ( $34,34 \%)$ dengan rincian peserta MOW $(1,51 \%)$, peserta IUD $(13,96 \%)$, peserta Implant sebanyak $(17,78 \%)$ dan peserta MOP $(1,09 \%)$.

Kabupaten Pesawaran merupakan salah satu dari 15 kabupaten/ kota yang ada di Provinsi Lampung pencapaian MKJP sebesar 19,28\% atau sekitar 16.795 PUS (BPS Provinsi Lampung Tahun 2015). Pencapaian MKJP tersebut masih dibawah dari beberapa Kabupaten di Provinsi Lampung seperti: Kabupaten Lampung Barat $(29,97 \%)$, Pringsewu $(23,16 \%)$, Tulang Bawang $(19,83 \%)$. Wilayah Kecamatan Negerikaton yang merupakan salah satu dari 11 kecamatan yang ada di Kabupaten Pesawaran didapat hasil MKJP pada tahun 2015 sebanyak 1.034 PUS (13,85\%) dengan Akseptor KB sebanyak 7.465 akseptor. Puskesmas Kalirejo sendiri yang merupakan salah satu puskesmas yang wilayah kerjanya berada di Kecamatan Negeri Katon dalam pencapaian MKJP cenderung menurun dalam waktu dua tahun terakhir (dari $11,07 \%$ pada tahun 2014 menjadi $10,87 \%$ pada tahun 2015 dan 10,62\% pada tahun 2016). Angka tersebut lebih rendah dibandingkan dengan pencapaian MKJP di tingkat Kabupaten $(19,28 \%)$. Pendataan prasurvey bulan Oktober 2016 (data 2015) untuk pencapaian MKJP menurun yakni sebesar 377 PUS atau sekitar 10,62\% dari 3551 akseptor KB.

Berdasarkan teori Green (2005) dan Notoatmodjo (2014) terdapat beberapa faktor yang berhubungan dengan penggunaan MKJP yakni faktor presdisposisi (Presdisposing factors) adalah faktor yang mempermudah dan mendasari untuk terjadinya prilaku tertentu. Faktor presdisposisi ini mencakup pengetahuan, sikap, kepercayaan,keyakinan dan nilai-nilai. Selain itu juga faktor presdisposisi meliputi umur, tingkat pendidikan, pekerjaan serta jumlah anak. Faktor pemungkin (Enabling factors) adalah faktor-faktor yang memungkinkan atau yang memfasilitasi perilaku atau tindakan.Faktor pemungkin adalah sarana dan prasarana atau fasilitas untuk terjadinya perilaku kesehatan misalnya Puskesmas, Posyandu, Rumah sakit, ketersediaan obat-obatan, ketersediaan alat-alat kontrasepsi dan sebagainya. Faktor penguat (Reinforcing factors) adalah faktor yang mendorong atau memperkuat terjadinya perilaku. Kadangkadang, meskipun seseorang tahu dan mampu untuk berperilaku sehat, tetapi tidak melakukannya. Faktorfaktor ini meliputi dukungan suami, pengaruh teman dan peranan petugas kesehatan.Dalam arti bahwa 
sikap seseorang bisa menentukan tindakan dan prilakunya.

Berdasarkan rendahnya cakupan MKJP tersebut yang melatarbelakangi dilakukan penelitian tentang determinan penggunaan metode kontrasepsi jangka panjang (MKJP) pada akseptor $\mathrm{KB}$ di wilayah kerja Puskesmas Kalirejo Kecamatan Negeri Katon Kabupaten Pesawaran Tahun 2017.

Tujuan dari penelitian ini adalah diketahui determinan penggunaan metode kontrasepsi jangka panjang (MKJP) pada akseptor KB di wilayah kerja Puskesmas Kalirejo Kecamatan Negeri Katon Kabupaten Pesawaran tahun 2017.

\section{METODE}

Rancangan penelitian analitik dengan pendekatan Cross Sectional. Penelitian Cross Sectional adalah suatu penelitian untuk mempelajari dinamika korelasi antara faktorfaktor risiko dengan efek, dengan cara pendekatan, observasi atau pengumpulan data sekaligus pada suatu saat (point time approach). Artinya, setiap subjek penelitian hanya diobservasi sekali saja dan pengukuran dilakukan terhadap status karakter atau variabel subjek pada saat pemeriksaan. Hal ini tidak berarti bahwa semua subjek penelitian diamati pada waktu yang sama (Notoatmodjo, 2012).

Penelitian ini dilaksanakan tanggal 1-31 April Tahun 2017 di wilayah Puskesmas Kalirejo Kecamatan Negeri Katon Kabupaten Pesawaran. Populasi dalam penelitian ini sebanyak 3551 akseptor KB aktif.Adapun besar sampel dalam penelitian ini dihitung dengan menggunakan rumus Slovin dan diperoleh sampel sebanyak 360 orang responden.Teknik pengambilan sampel dalam penelitian ini adalah Quota Sampling.

Dalam penelitian ini variabel dependen adalah penggunaan metode kontrasepsi jangka panjang (MKJP) dan variabel independen adalah determinan penggunaan metode kontrasepsi jangka panjang (MKJP). Instrumen yang digunakan dalam penelitian ini adalah kuesioner.

\section{HASIL}

Tabel 1. Distribusi Frekuensi Variabel Dependen dan Independen Akseptor KB

\begin{tabular}{|c|c|c|}
\hline Variabel & $\mathbf{n}$ & $\%$ \\
\hline \multicolumn{3}{|l|}{ Penggunaan MKJP } \\
\hline • MKJP & 87 & 24,7 \\
\hline - Non-MKJP & 271 & 75,3 \\
\hline \multicolumn{3}{|l|}{ Umur } \\
\hline - Berisiko & 206 & 57,2 \\
\hline - Tidak berisiko & 154 & 42,8 \\
\hline \multicolumn{3}{|l|}{ Pekerjaan } \\
\hline - Bekerja & 156 & 43,3 \\
\hline - Tidak bekerja & 204 & 56,7 \\
\hline \multicolumn{3}{|l|}{ Jumlah Anak } \\
\hline - Berisiko & 235 & 65,3 \\
\hline - Tidak berisiko & 125 & 34,7 \\
\hline \multicolumn{3}{|l|}{ Dukungan } \\
\hline Suami/Pasangan & 301 & 83.6 \\
\hline $\begin{array}{l}\text { - Didukung } \\
\text { - Tidak didukung }\end{array}$ & 59 & 16,4 \\
\hline
\end{tabular}

Tabel 2. Determinan Penggunaan Metode Kontrasepsi Jangka Panjang (MKJP) pada Akseptor KB

\begin{tabular}{|c|c|c|c|c|c|c|}
\hline \multirow{3}{*}{ Variabel } & \multicolumn{4}{|c|}{ Penggunaan Kontrasepsi } & \multirow{3}{*}{ OR $(95 \% \mathrm{CI})$} & \multirow{3}{*}{$p$-value } \\
\hline & \multicolumn{2}{|c|}{ MKJP } & \multicolumn{2}{|c|}{ Non MKJP } & & \\
\hline & $\mathbf{n}$ & $\%$ & $\mathbf{n}$ & $\%$ & & \\
\hline \multicolumn{7}{|l|}{ Umur } \\
\hline Berisiko & 40 & 19,4 & 166 & 80,6 & & \\
\hline Tidak berisiko & 49 & 31,8 & 105 & 68,2 & $1,937(1,194-3,142)$ & 0,007 \\
\hline \multicolumn{7}{|l|}{ Pekerjaan } \\
\hline Bekerja & 74 & 47,4 & 82 & 52,6 & & \\
\hline Tidak bekerja & 15 & 7,4 & 189 & 92,6 & $11,371(6,163-20,980)$ & 0,000 \\
\hline \multicolumn{7}{|l|}{ Jumlah Anak } \\
\hline Berisiko & 63 & 26,8 & 172 & 73,2 & & \\
\hline Tidak berisiko & 26 & 20,8 & 99 & 79,2 & - & 0,208 \\
\hline \multicolumn{7}{|c|}{ Dukungan Suami } \\
\hline Didukung & 53 & 17,6 & 248 & 82,4 & & \\
\hline Tidak didukung & 36 & 61,0 & 23 & 39,0 & $0.137(0,075-0,249)$ & 0,000 \\
\hline
\end{tabular}




\section{PEMBAHASAN}

Hubungan Umur dengan Penggunaan Metode Kontrasepsi Jangka Panjang (MKJP) pada Akseptor KB

Hasil uji statistik diperoleh $p$-value $=0,007$ yang berarti $p<0,05$, maka hal ini dapat disimpulkan bahwa ada hubungan yang bermakna antara umur dengan penggunaan metode kontrasepsi jangka panjang (MKJP) pada akseptor KB di wilayah kerja Puskesmas Kalirejo Kecamatan Negeri Katon Kabupaten Pesawaran Tahun 2017. Dari analisis keeratan hubungan tersebut menunjukkan nilai Odd Ratio (OR) 1.937, berarti bahwa responden yang memiliki umur berisiko berpeluang 1,937 kali lebih besar untuk menggunakan metode kontrasepsi jangka panjang (MKJP) dibandingkan dengan responden yang memiliki umur tidak berisiko.

Menurut pendapat peneliti semakin dewasa seseorang maka sangat mempengaruhi keputusannya dalam menggunakan kontrasepsi khususnya kontrasepsi jangka panjang atau MKJP.

Hubungan Pekerjaan dengan Penggunaan Metode Kontrasepsi Jangka Panjang (MKJP) pada akseptor KB

Hasil uji statistik diperoleh $p$-value $=0,000$ yang berarti $p<0,05$, maka hal ini dapat disimpulkan bahwa ada hubungan yang bermakna antara pekerjaan dengan penggunaan metode kontrasepsi jangka panjang (MKJP) pada akseptor KB di wilayah kerja Puskesmas Kalirejo Kecamatan Negeri Katon Kabupaten Pesawaran Tahun 2017. Dari analisis keeratan hubungan tersebut menunjukkan nilai Odd Ratio (OR) 11,371, berarti bahwa responden yang tidak bekerja berpeluang 11,371 kali lebih besar untuk menggunakan metode kontrasepsi jangka panjang (MKJP) dibandingkan dengan responden yang bekerja.

Menurut pendapat peneliti, dengan bekerjanya seseorang maka akan memperluas pengetahuan serta makin banyak informasi yang didapat oleh orang tersebut dan nantinya akan mempermudah orang tersebut dalam menentukan kontrasepsi yang efektif serta efisien yakni MKJP.

\section{Hubungan Jumlah Anak dengan Penggunaan Metode Kontrasepsi Jangka Panjang (MKJP) pada Akseptor KB}

Hasil uji statistik diperoleh $p$-value $=0,208$ yang berarti $p>0,05$, maka hal ini dapat disimpulkan bahwa tidak ada hubungan antara jumlah anak dengan penggunaan metode kontrasepsi jangka panjang (MKJP) pada akseptor KB di wilayah kerja Puskesmas Kalirejo Kecamatan Negeri Katon Kabupaten Pesawaran Tahun 2017.

Menurut pendapat peneliti, paritas yang beresiko maupun tidak beresiko memerlukan informasi yang tepat tentang kontrasepsi MKJP maupun non MKJP. Karena dengan informasi $\mathrm{KB}$ yang tepat, maka aksreptor KB baik yang baru maupun aktif dengan paritas beresiko maupun tidak beresiko dapat dengan mudah mementukan jenis kontrasepsi yang tepat untuknya.

\section{Hubungan Dukungan Suami/ Pasangan dengan Penggunaan Metode Kontrasepsi Jangka Panjang (MKJP) pada Akseptor KB}

Hasil uji statistik diperoleh $p$-value $=0,000$, maka hal ini dapat disimpulkan bahwa ada hubungan yang bermakna antara dukungan suami/ pasangan dengan penggunaan metode kontrasepsi jangka panjang (MKJP) pada akseptor KB di wilayah kerja Puskesmas Kalirejo Kecamatan Negeri Katon Kabupaten Pesawaran Tahun 2017.

Peneliti berpendapat bahwa suami/ pasangan hendaknya memiliki pengetahuan yang lebih tentang kontrasepsi khususnya MKJP, karena dengan pengetahuan yang lebih tersebut akan dapat memberikan perhatian serta izin kepada pasangannya dalam penggunaan kontrasepsi. Karena itu dukungan suami atau pasangan sangatlah penting pada akseptor KB dalam penggunaan kontrasepsi MKJP guna mempertahankan perilaku akseptor KB untuk dapat tetap menggunakan MKJP.

\section{SIMPULAN}

1. Sebagian besar responden menggunakan kontrasepsi Non MKJP sebanyak 271 $(75,3 \%)$. Sebagian besar responden memiliki umur beresiko sebanyak 205 (57,2\%), tidak bekerja 204 (56,7\%), dan jumlah anak beresiko 235 (65,3\%). Sebagian besar responden menyatakan didukung suami/ pasangan yaitu sebanyak $301(83,6 \%)$. 
2. Ada hubungan umur $(p=0,007)$, pekerjaan $(p=0,000)$, dukungan suami/ pasangan $(p=0,000)$ dengan penggunaan metode kontrasepsi jangka panjang (MKJP) pada akseptor KB di wilayah kerja Puskesmas Kalirejo Kecamatan Negeri Katon Kabupaten Pesawaran Tahun 2017.

3. Tidak ada hubungan jumlah anak $(p=0,208)$ dengan penggunaan metode kontrasepsi jangka panjang (MKJP) pada akseptor KB di wilayah kerja Puskesmas Kalirejo Kecamatan Negeri Katon Kabupaten Pesawaran Tahun 2017.

\section{SARAN}

1. Puskesmas Kalirejo Kecamatan Negeri Katon Kabupaten Pesawaran

Dari hasil penelitian yang telah dilakukan hendaknya institusi kesehatan dapat kiranya:

a. Meningkatkan pengetahuan pada akseptor KB baik yang baru maupun aktif tentang kontrasepsi MKJP, pemberian penyuluhan tentang KB-MKJP di Kelas Ibu Bayi dan Balita serta di posyandu balita yang diadakan di semua desa binaan setiap bulannya.

b. Kepada petugas kesehatan lebih meningkatkan pelayanan kontrasepsi

\section{DAFTAR PUSTAKA}

BKKBN. 2015. Rencana Strategis Badan Kependudukan dan Keluarga Berencana Nasional Tahun 2015-2019. Jakarta.

BKKBN. 2015. Rapat Pengendalian Program dan Anggaran Data Januari 2015, Direktorat Pelaporan dan Statistik. Jakarta.

Green. W. Lawrence. et.all 2005. Health Education Planning Diagnostik Approach, The Johns Hapkins University: Mayfield Publishing Company.

Hartanto.W. 2016. Analisis Data Kependudukan dan KB Hasil Susenas 2015. Rapat kepada akseptor $\mathrm{KB}$ baik yang baru maupun aktif dengan cara memberikan informasi terbaru serta konseling KBMKJP guna meningkatkan cakupan penggunaan MKJP di wilayah kerjanya.

c. Pihak Puskesmas Kalirejo hendaknya tetap melakukan pembinaan kepada akseptor KB aktif yang menggunakan MKJP agar tetap sebagai percontohan (role model) bagi calon akseptor yang baru. Dengan demikian nantinya dapat meningkatkan cakupan pelayanan MKJP di wilayah kerjanya.

2. Bagi peneliti lainnya

Diharapkan kepada peneliti lainnya dapat melanjutkan penelitian yang telah dilakukan dengan menambah variabel-variabel yang belum sempat tergali oleh peneliti guna peningkatan pemakaian MKJP. Serta kedepannya para peneliti lainnya dapat menyempurnakan alat bantu penelitian berupa kuesioner, sehingga mendapatkan data-data yang secara teoritis sangat mempengaruhi penggunaan kontrasepsi MKJP. Dengan demikian nantinya dapat meningkatkan cakupan penggunaan metode kontrasepsi jangka panjang (MKJP) di tempat penelitiannya tersebut.

Koordinasi Nasional (Rakornas) BKKBN, Jakarta.

Manuaba. 2009. Memahami Kesehatan Reproduksi Wanita. Jakarta: ECG.

Manuaba. 2010. Ilmu Kebidanan, Penyakit Kandungan dan KB. Jakarta: ECG.

Notoatmodjo, S. 2012. Metodologi penelitian kesehatan, Jakarta: Rineka Cipta.

Notoatmodjo, S. 2014. Ilmu Perilaku Kesehatan, Jakarta: Rineka Cipta.

Pendataan Keluarga. 2015. Rekapitulasi Hasil Pendataan Keluarga Tahun 2015, Kabupaten Pesawaran. 